\title{
Optical, TSL, and OSL Properties of Copper-doped Cesium Bromide Transparent Ceramics Prepared by SPS
}

\author{
Hiromi Kimura, ${ }^{*}$ Takumi Kato, Daisuke Nakauchi, \\ Noriaki Kawaguchi, and Takayuki Yanagida \\ Division of Materials Science, Nara Institute of Science and Technology (NAIST), \\ 8916-5 Takayama-cho, Ikoma-shi, Nara 630-0192, Japan
}

(Received January 31, 2021; accepted May 7, 2021)

Keywords: photoluminescence, thermally stimulated luminescence, optically stimulated luminescence, transparent ceramics

The optical, thermally stimulated luminescence (TSL), and optically stimulated luminescence (OSL) properties of $\mathrm{CsBr}: \mathrm{Cu}$ transparent ceramics were evaluated. As the photoluminescence properties, two emissions around 460 and $490 \mathrm{~nm}$ related to $\mathrm{Cu}^{+}$and $\mathrm{Cu}^{2+}$ ions, respectively, were observed under excitation at around $300 \mathrm{~nm}$, and the quantum yield of $\mathrm{CsBr}: \mathrm{Cu}(0.01 \%)$ was $17.3 \%$. After X-ray irradiation, all the samples showed a broad TSL and OSL emission band around 400-500 $\mathrm{nm}$. All the samples exhibited good proportionality in the TSL and OSL dose response functions in the dose ranges of $0.01-100$ and 1-1000 mGy, respectively.

\section{Introduction}

Bulk inorganic phosphors have been utilized to measure ionizing radiation, and they are mainly classified into scintillators and storage phosphors. ${ }^{(1)}$ Scintillators convert ionizing radiation such as $\mathrm{X}$ - and $\gamma$-rays into numerous ultraviolet-visible photons, then the converted photons can be detected by photodetectors such as photodiodes and photomultiplier tubes. Bulk inorganic phosphors have been used in various fields, including security, ${ }^{(2)}$ medical imaging, ${ }^{(3)}$ well logging, ${ }^{(4)}$ astrophysics, ${ }^{(5)}$ and particle physics. ${ }^{(6)}$ On the other hand, storage phosphors temporarily store the incident radiation dose, and then the stored energy can be released by external simulation to emit photons. The photons obtained by the stimulation of heat or light are called thermally stimulated luminescence (TSL) and optically stimulated luminescence (OSL), respectively. ${ }^{(7)}$ Since the TSL and OSL intensities are proportional to the incident radiation dose, storage phosphors are used for personal dose monitoring ${ }^{(8-13)}$ and imaging plates. ${ }^{(14-19)}$

So far, most research on scintillators and storage phosphors has been on various material forms including single crystals, ${ }^{(20-24)}$ glasses, ${ }^{(25-29)}$ and opaque ceramics. ${ }^{(30-32)}$ In recent years, transparent ceramics have attracted much attention as a new material form. ${ }^{(33-36)}$ When a scintillator or storage phosphor is transparent, luminescence can be detected from not only the surface but also inside the material. Additionally, transparent ceramics generally have a lower

*Corresponding author: e-mail: kimura.hiromi.kf1@ms.naist.jp

https://doi.org/10.18494/SAM.2021.3322 
sintering temperature, higher uniformity of the dopant, and higher mechanical strength than single crystals. In particular, we found that the TSL and OSL properties of transparent ceramics synthesized by spark plasma sintering (SPS) were enhanced in some materials, ${ }^{(37-39)}$ since the SPS was performed in a highly reductive environment, which effectively generates defect centers. However, there are few reports on the TSL and OSL properties of transparent ceramics synthesized by SPS.

In this study, we focused on $\mathrm{CsBr}$, which is a promising host material for storage phosphors because of its effective X-ray absorption. ${ }^{(40,41)}$ According to previous reports, $\mathrm{CsBr}$ :Cu crystals show strong OSL emission in the blue to green region. ${ }^{(42,43)}$ However, there are no reports on $\mathrm{CsBr}: \mathrm{Cu}$ in the transparent ceramic form. Therefore, we synthesized $\mathrm{CsBr}: \mathrm{Cu}$ transparent ceramics by SPS and investigated their optical, TSL, and OSL properties.

\section{Experimental Procedure}

$\mathrm{CsBr}: \mathrm{Cu}(0.01,0.1$, and $1 \%)$ transparent ceramics were synthesized by SPS using raw powders of $\mathrm{CsBr}$ (99.99\%, Furuuchi Chemical) and $\mathrm{CuCl}_{2} \cdot 2 \mathrm{H}_{2} \mathrm{O}$ (99.99\%, Kojundo Chemical Laboratory). These powders were mixed and loaded in a cylindrical graphite die and held between two graphite punches. As shown in Fig. 1, the temperature of the SPS equipment was increased from 20 to $450{ }^{\circ} \mathrm{C}$ at a rate of $43{ }^{\circ} \mathrm{C} / \mathrm{min}$, then maintained at $450{ }^{\circ} \mathrm{C}$ for $10 \mathrm{~min}$ while applying a pressure of $6 \mathrm{MPa}$. After sintering, the surfaces of samples were mechanically polished with sandpaper.

To evaluate the optical properties of the samples, in-line transmittance spectra were obtained by a spectrophotometer (SolidSpec-3700, Shimadzu). Photoluminescence (PL) excitation and emission maps as well as the PL quantum yield $(Q Y)$ were obtained using an absolute PL quantum yield spectrometer (Quantaurus-QY C11347, Hamamatsu Photonics). PL decay curves were obtained using a fluorescence lifetime spectrometer (Quantaurus-Tau C11367, Hamamatsu Photonics). The TSL spectrum as a function of temperature was measured using a customized setup. $^{(44,45)}$ To obtain the TSL dose response function, the TSL signal was obtained using a commercial TSL reader (TL-2000, Nanogray) after various irradiation doses. ${ }^{(46)}$ As the radiation source, we used an X-ray generator (XRB80P \&N200×4550, Spellman) equipped with a

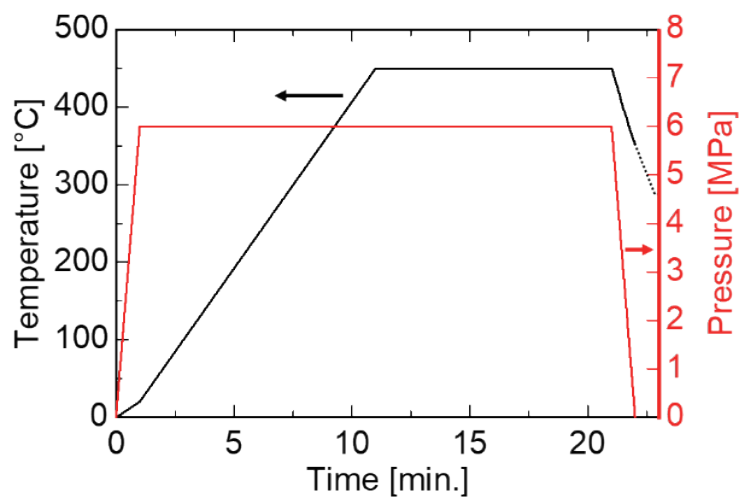

Fig. 1. (Color online) SPS processing conditions. 
conventional X-ray tube having a W anode target. The X-ray tube was operated with a tube voltage of $40 \mathrm{kV}$, and the irradiated dose was calibrated using an air-filled ionization chamber (TN30013, PTW). OSL emission and stimulation maps of $\mathrm{CsBr}: \mathrm{Cu}$ transparent ceramics after $\mathrm{X}$-ray irradiation (10 Gy) were obtained using a spectrometer. The OSL dose response function was obtained using a spectrofluorometer (FP-8600, JASCO) after X-ray irradiation with various doses during stimulation at $630 \mathrm{~nm} .{ }^{(47)}$

\section{Results and Discussion}

Figure 2 shows photographs of the $\mathrm{CsBr}: \mathrm{Cu}$ transparent ceramics under room light and 302 $\mathrm{nm}$ excitation. When the sample thickness was fixed at $10 \mathrm{~mm}$, all the samples were transparent. Under $302 \mathrm{~nm}$ excitation, all the samples produced a verdigris-colored emission. In-line transmittance spectra of the $\mathrm{CsBr}: \mathrm{Cu}$ transparent ceramics are shown in Fig. 3. The transmittance increased with increasing $\mathrm{Cu}$ concentration.

For all the samples, absorption bands were observed around 275 and $315 \mathrm{~nm}$. Since the absorption bands were similar to those reported for $\mathrm{CsBr}: \mathrm{CuBr}_{2}$ and $\mathrm{CsBr}: \mathrm{CuO}$ crystals, their origin was concluded to be $3 \mathrm{~d}^{9} 4 \mathrm{~s}-3 \mathrm{~d}^{10}$ transitions of $\mathrm{Cu}^{+}$and $\mathrm{Cu}^{2+}$ ions, respectively. ${ }^{(42,43)}$

Figure 4 shows PL excitation and emission maps of the $\mathrm{CsBr}: \mathrm{Cu}$ transparent ceramics. Two excitation bands were observed around 275 and $315 \mathrm{~nm}$, consistent with the absorption bands. The $\mathrm{CsBr}: \mathrm{Cu}$ samples showed a broad emission band around $460 \mathrm{~nm}$ under $275 \mathrm{~nm}$ excitation, while all the samples exhibited a broad emission band around $490 \mathrm{~nm}$ under $315 \mathrm{~nm}$ excitation. The spectral shapes were similar to those in previous reports on $\mathrm{CsBr}: \mathrm{CuO}$ and $\mathrm{CsBr}: \mathrm{CuBr}_{2}$ crystals, and the emissions around 460 and $490 \mathrm{~nm}$ were considered to be related to $\mathrm{Cu}^{+}$and $\mathrm{Cu}^{2+}$ ions, respectively. ${ }^{(42,43)} \mathrm{OH}^{-}$ions and oxygen impurities may have existed in the matrix because $\mathrm{CuCl}_{2} \cdot 2 \mathrm{H}_{2} \mathrm{O}$ was used as a starting powder. The $Q Y$ values of $\mathrm{CsBr}: \mathrm{Cu}(0.01,0.1$, and $1 \%$ ) were $17.3,14.4$, and $12.2 \%$, respectively, which were higher than those of $\mathrm{CsBr}: \mathrm{Eu}$ transparent ceramics $(0.8-3.4 \%){ }^{(48)}$

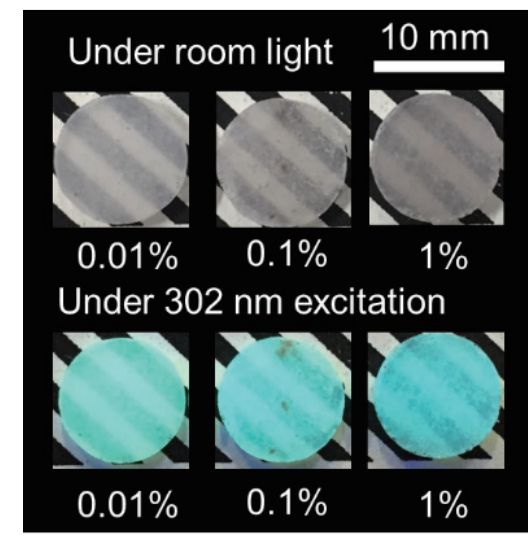

Fig. 2. (Color online) Photographs of $\mathrm{CsBr}: \mathrm{Cu}$ transparent ceramics under room light and $302 \mathrm{~nm}$ excitation.

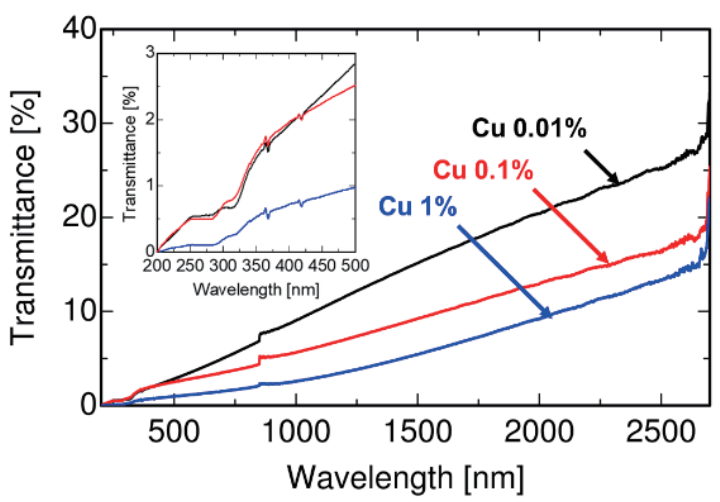

Fig. 3. (Color online) In-line transmittance spectra of $\mathrm{CsBr}: \mathrm{Cu}$ transparent ceramics. The inset is an enlargement of the 200-500 $\mathrm{nm}$ region. 


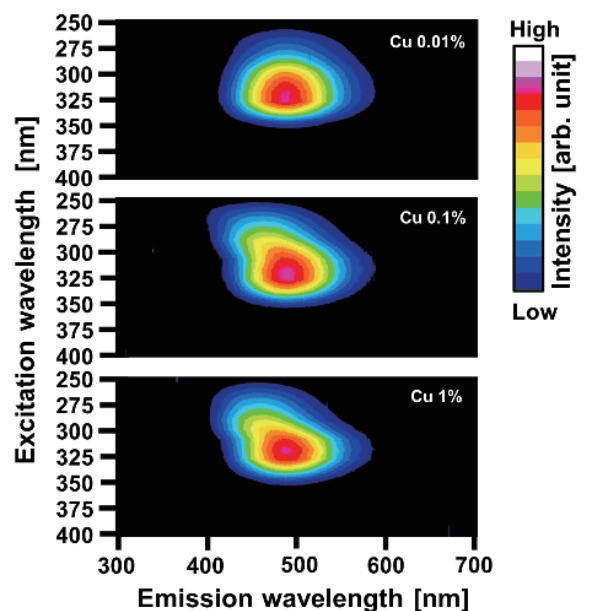

Fig. 4. (Color online) PL excitation and emission maps of $\mathrm{CsBr}: \mathrm{Cu}$ transparent ceramics.

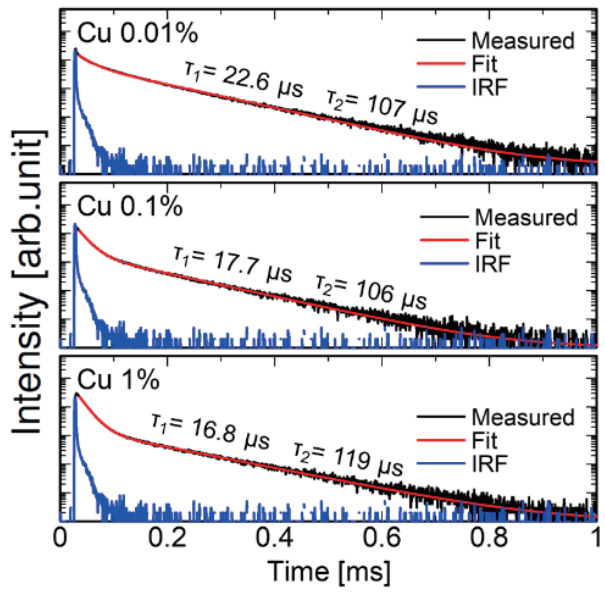

Fig. 5. (Color online) PL decay curves of $\mathrm{CsBr}: \mathrm{Cu}$ transparent ceramics.

$\mathrm{PL}$ decay curves of the $\mathrm{CsBr}: \mathrm{Cu}$ transparent ceramics are presented in Fig. 5. The monitoring and excitation wavelengths were 490 and $265 \mathrm{~nm}$, respectively. The decay time constants were obtained by fitting the tail part of the decay curves with the sum of two exponential decay functions to avoid the influence of the instrumental response function (IRF). The obtained faster and slower components were 16.8-22.6 and 106-119 $\mu$ s, respectively, consistent with the values in previous reports on $\mathrm{CsBr}: \mathrm{CuO}$ crystal and $\mathrm{Cu}$-doped materials. ${ }^{(42,49,50)}$

Figure 6 shows the TSL spectrum as a function of the temperature of the $\mathrm{CsBr}: \mathrm{Cu}$ transparent ceramics after X-ray irradiation (10 Gy). TSL glow peaks appeared at around 85 and $150{ }^{\circ} \mathrm{C}$, and the intensity of the peak at around $150{ }^{\circ} \mathrm{C}$ increased with increasing $\mathrm{Cu}$ concentration. Similar glow peaks have been observed for Eu-doped $\mathrm{CsBr}$. Thus, the peak was considered to originate from the CsBr host. ${ }^{(51)}$ All the samples showed a broad emission band around 400-500 $\mathrm{nm}$ in the TSL spectra, consistent with a previous study. ${ }^{(52)}$ Judging from the spectral shapes, the emission originated from $3 \mathrm{~d}^{10}-3 \mathrm{~d}^{9} 4 \mathrm{~s}$ transitions of the $\mathrm{Cu}^{+}$ion. ${ }^{(42,49,50)}$ TSL dose response functions of $\mathrm{CsBr}: \mathrm{Cu}$ transparent ceramics are shown in Fig. 7. All the samples showed good proportionality in the dose range of 0.01 to $100 \mathrm{mGy}$. The detection limit was comparable to that of commercial personal dosimeters. ${ }^{(53)}$

Figure 8 presents OSL emission and stimulation maps of the $\mathrm{CsBr}: \mathrm{Cu}$ transparent ceramics. An OSL emission band around 400-500 nm was observed under stimulation with a wavelength of $620 \mathrm{~nm}$. Since the spectral features were similar to those of the TSL, the origin of the emission was considered to be the same. However, the intensity of the peak around $500 \mathrm{~nm}$ due to $\mathrm{Cu}^{2+}$ ions was lower than that for the $\mathrm{CsBr}: \mathrm{Cu}$ crystal in previous reports. ${ }^{(42)}$ This may have been because the amount of $\mathrm{Cu}^{2+}$ ions was smaller than that in previous studies since SPS was performed in a highly reductive atmosphere in the previous studies. OSL dose response functions of the $\mathrm{CsBr}: \mathrm{Cu}$ transparent ceramics are shown in Fig. 9. All the samples exhibited dose response functions with a good proportional relationship in the range of 1-1000 mGy, and the detection limit was less than that of $\mathrm{CsBr}$ :Eu transparent ceramics. ${ }^{(48)}$ Since the detection 


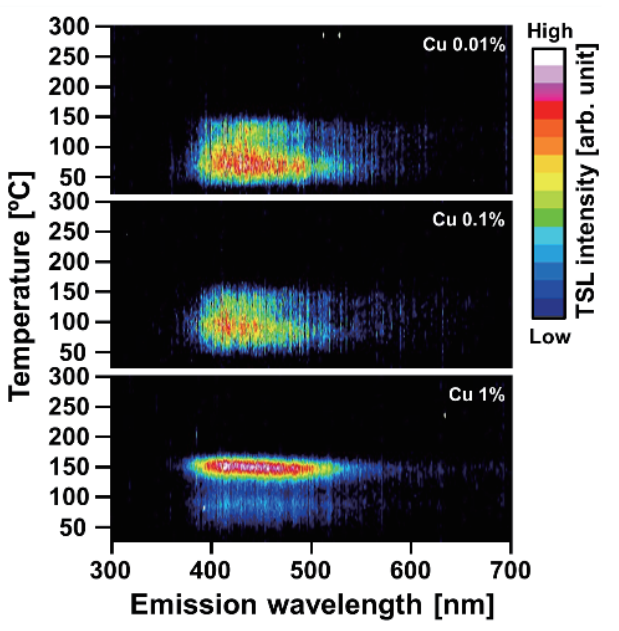

Fig. 6. (Color online) TSL spectrum as a function of temperature of $\mathrm{CsBr}: \mathrm{Cu}$ transparent ceramics after $\mathrm{X}$-ray irradiation (10 Gy).

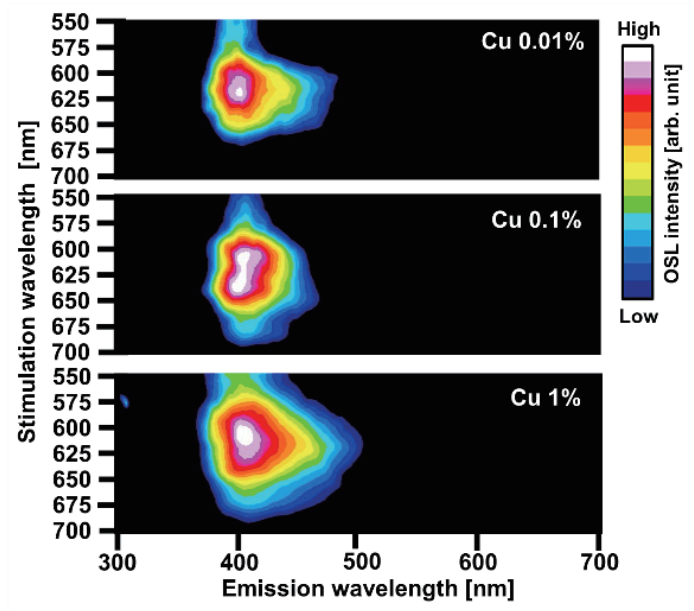

Fig. 8. (Color online) OSL emission and stimulation maps of $\mathrm{CsBr}: \mathrm{Cu}$ transparent ceramics.

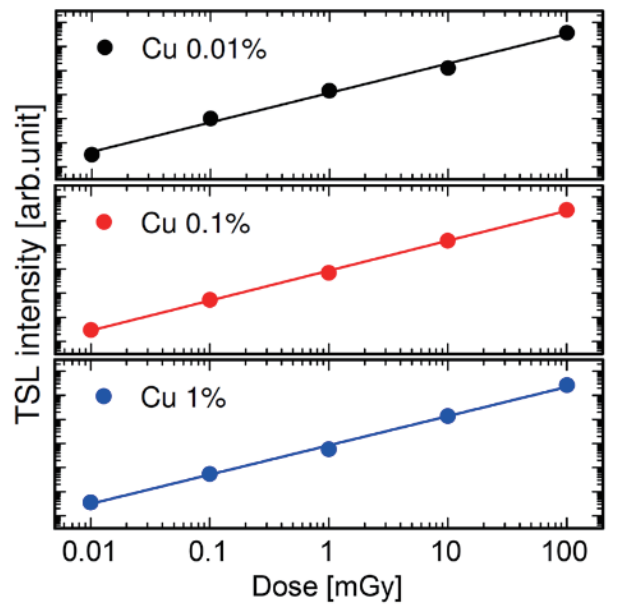

Fig. 7. (Color online) TSL dose response functions of $\mathrm{CsBr}: \mathrm{Cu}$ transparent ceramics.

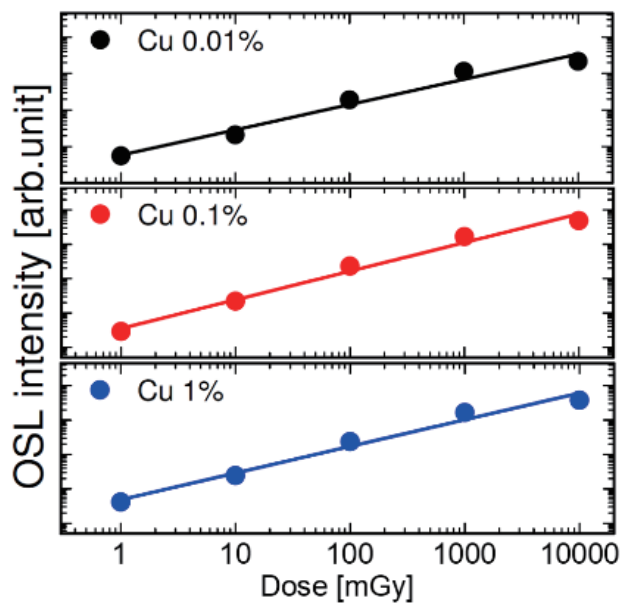

Fig. 9. (Color online) OSL dose response functions of $\mathrm{CsBr}: \mathrm{Cu}$ transparent ceramics.

limit depends on the measurement setup, it is expected that the detection sensitivity can be improved by optimizing OSL readers.

\section{Conclusions}

$\mathrm{CsBr}: \mathrm{Cu}$ transparent ceramics were synthesized by SPS, and their optical, TSL, and OSL properties were investigated. Under excitation at around $300 \mathrm{~nm}$, all the samples showed PL emission bands around 275 and $315 \mathrm{~nm}$, which were related to $\mathrm{Cu}^{+}$and $\mathrm{Cu}^{2+}$ ions, respectively. TSL and OSL emission bands were observed around 400-500 $\mathrm{nm}$. Although the spectral shapes 
of the samples were consistent with that of the $\mathrm{CsBr}: \mathrm{Cu}$ crystal, the intensity of the peak around $500 \mathrm{~nm}$ due to $\mathrm{Cu}^{2+}$ ions was lower than that of the $\mathrm{CsBr}: \mathrm{Cu}$ crystal. For all the samples, the dose sensitivities using TSL and OSL were confirmed to be as low as 0.01 and $1 \mathrm{mGy}$, respectively. The detection limit using TSL was comparable to that of commercial products.

\section{Acknowledgments}

This work was supported by Grants-in-Aid for Scientific Research A (17H01375), Scientific Research B (18H03468), and JSPS Research Fellowship (19J22091) from JSPS. The Cooperative Research Project of the Research Center for Biomedical Engineering, Iketani Foundation, and Nippon Sheet Glass Foundation are also acknowledged.

\section{References}

1 T. Yanagida: Proc. Japan Acad. Ser. B 94 (2018) 75.

2 J. Glodo, Y. Wang, R. Shawgo, C. Brecher, R. H. Hawrami, J. Tower, and K. S. Shah: Phys. Procedia 90 (2017) 285.

3 C. W. E. van Eijk: Phys. Med. Biol. 47 (2002) R85.

4 N. Kawaguchi, G. Okada, K. Fukuda, and T. Yanagida: Nucl. Instrum. Methods Phys. Res., Sect. A 954 (2020) 161518.

5 H. Takahashi, T. Yanagida, D. Kasama, T. Ito, M. Kokubun, K. Makishima, T. Yanagitani, H. Yagi, T. Shigeta, and T. Ito: IEEE Trans. Nucl. Sci. 53 (2006) 2404.

6 T. Itoh, T. Yanagida, M. Kokubun, M. Sato, R. Miyawaki, K. Makishima, T. Takashima, T. Tanaka, K. Nakazawa, T. Takahashi, N. Shimura, and H. Ishibashi: Nucl. Instrum. Methods Phys. Res., Sect. A 579 (2007) 239.

7 T. Yanagida, G. Okada, and N. Kawaguchi: J. Lumin. 207 (2019) 14.

8 S. Yanagisawa, D. Maruyama, R. Oh, Y. Koba, T. Andoh, and K. Shinsho: Sens. Mater. 32 (2020) 1479.

9 S. W. S. McKeever: Radiat. Meas. 46 (2011) 1336.

10 L. E. Colyott, M. S. Akselrod, and S. W. S. McKeever: Radiat. Prot. Dosimetry 72 (1997) 87.

11 P. Covens, D. Berus, N. Buls, P. Clerinx, and F. Vanhavere: Radiat. Prot. Dosimetry 124 (2007) 250.

12 M. S. Akselrod, L. Bøtter-Jensen, and S. W. S. McKeever: Radiat. Meas. 41 (2006) 78.

13 C. C. Gronchi, S. G. P. Cecatti, T. C. N. O. Pinto, and L. V. E. Caldas: Nucl. Instrum. Methods Phys. Res., Sect. B 266 (2008) 2915.

14 H. Nanto: Sens. Mater. 30 (2018) 327.

15 A. Boukhair, C. Heilmann, A. Nourreddine, A. Pape, and G. Portal: Radiat. Meas. 34 (2001) 513.

16 S. V. Moharil: Bull. Mater. Sci. 17 (1994) 25.

17 P. Leblans, D. Vandenbroucke, and P. Willems: Materials 4 (2011) 1034.

18 H. Ohuchi and A. Yamadera: Radiat. Meas. 35 (2002) 135.

19 D. Maruyama, S. Yanagisawa, Y. Koba, T. Andou, and K. Shinsho: Sens. Mater. 32 (2020) 1461.

20 T. Yanagida, Y. Fujimoto, M. Arai, M. Koshimizu, T. Kato, D. Nakauchi, and N. Kawaguchi: Sens. Mater. 32 (2020) 1351.

21 B. Liu: Chin. Sci. Bull. 47 (2002) 1057.

22 D. Nakauchi, T. Kato, N. Kawaguchi, and T. Yanagida: Sens. Mater. 32 (2020) 1389.

23 P. Kantuptim, M. Akatsuka, D. Nakauchi, T. Kato, N. Kawaguchi, and T. Yanagida: Sens. Mater. 32 (2020) 1357.

24 Y. Fujimoto, K. Saeki, D. Nakauchi, T. Yanagida, M. Koshimizu, and K. Asai: Sens. Mater. 31 (2019) 1241.

25 A. M. Bishay: J. Am. Ceram. Soc. 44 (1961) 231.

26 D. Shiratori, D. Nakauchi, T. Kato, N. Kawaguchi, and T. Yanagida: Sens. Mater. 32 (2020) 1365.

27 L.Q. Nguyen, G. Gabella, B. L. Goldblum, T. A. Laplace, J. S. Carlson, E. Brubaker, and P. L. Feng: Nucl. Instrum. Methods Phys. Res., Sect. A 988 (2021) 164898.

28 N. Kawaguchi and T. Yanagida: Sens. Mater. 31 (2019) 1257.

29 H. Kimura, H. Masai, T. Kato, D. Nakauchi, N. Kawaguchi, and T. Yanagida: J. Mater. Sci. Mater. Electron. 31 (2020) 3017. 
30 A.. Lakshmanan, N. Murase, T. Yazawa, J. Qiu, T. Mitsuyu, K. Hirao, A. Tomita, and W. Hoffmann: Radiat. Meas. 33 (2001) 119.

31 S. Yamamoto and H. Tomita: Appl. Radiat. Isot. 168 (2021) 109527.

32 N. M. Winch and A. Edgar: Nucl. Instrum. Methods Phys. Res., Sect. A 654 (2011) 308.

33 D. Jiang, D. M. Hulbert, U. Anselmi-Tamburini, T. Ng, D. Land, and A. K. Mukherjee: J. Am. Ceram. Soc. 91 (2007) 151.

34 T. Yanagida, K. Kamada, Y. Fujimoto, H. Yagi, and T. Yanagitani: Opt. Mater. 35 (2013) 2480.

35 A. Ikesue and Y.L. Aung: Nat. Photonics 2 (2008) 721.

36 H. Kimura, T. Kato, D. Nakauchi, N. Kawaguchi, and T. Yanagida: Sens. Mater. 32 (2020) 1381.

37 T. Kato, G. Okada, and T. Yanagida: Ceram. Int. 42 (2016) 5617.

38 H. Kimura, T. Kato, D. Nakauchi, M. Koshimizu, N. Kawaguchi, and T. Yanagida: Sens. Mater. 31 (2019) 1265.

39 F. Nakamura, T. Kato, G. Okada, N. Kawaguchi, K. Fukuda, and T. Yanagida: J. Eur. Ceram. Soc. 37 (2017) 1707.

40 H. Kimura, T. Kato, D. Nakauchi, G. Okada, N. Kawaguchi, and T. Yanagida: Nucl. Instrum. Methods Phys. Res., Sect. A 954 (2020) 161226.

41 H. Kimura, T. Kato, D. Nakauchi, N. Kawaguchi, and T. Yanagida: Opt. Mater. 100 (2020) 109660.

42 Y. Zorenko, R. Turchak, T. Voznjak, M. Batentschuk, A. Osvet, and A. Winnacker: Phys. Status Solidi Appl. Mater. Sci. 202 (2005) 2537.

43 Y. Zorenko, R. Turchak, T. Voznyak, V. Savchin, M. Batenchuk, and A. Winnacker: Crystallogr. Rep. 51 (2006) 329.

44 G. Okada, N. Kawaguchi, and T. Yanagida: Opt. Mater. 87 (2019) 84.

45 Y. Isokawa, H. Kimura, T. Kato, N. Kawaguchi, and T. Yanagida: Opt. Mater. 90 (2019) 187.

46 T. Yanagida, Y. Fujimoto, N. Kawaguchi, and S. Yanagida: J. Ceram. Soc. Jpn. 121 (2013) 988.

47 H. Kimura, F. Nakamura, T. Kato, D. Nakauchi, N. Kawano, G. Okada, N. Kawaguchi, and T. Yanagida: J. Ceram. Soc. Jpn. 126 (2018) 184.

48 H. Kimura, T. Kato, M. Akatsuka, D. Nakauchi, G. Okada, N. Kawaguchi, and T. Yanagida: Radiat. Meas. 135 (2020) 106367.

49 D. Shiratori, Y. Isokawa, N. Kawaguchi, and T. Yanagida: Sens. Mater. 31 (2019) 1281.

50 H. Masai, H. Ofuchi, G. Okada, N. Kawaguchi, and T. Yanagida: Sens. Mater. 31 (2019) 1297.

51 H. Kimura, F. Nakamura, T. Kato, D. Nakauchi, N. Kawano, G. Okada, N. Kawaguchi, and T. Yanagida: Optik 157 (2018) 421.

52 B. V. R. Chowdari and S. Selvasekarapandian: Cryst. Lattice Defects 9 (1980) 31.

53 D. Y. C. Huang and S.-M. Hsu: Adv. Cancer Ther. InTech (2011). 